\title{
Glucose-Fueled Peptide Assembly: Glucagon Delivery via Enzymatic Actuation
}

\author{
Sihan Yu, ${ }^{\dagger}$ Sijie Xian, ${ }^{\dagger}$ Zhou Ye, ${ }^{\dagger}$ Irawan Pramudya, ${ }^{\dagger}$ Matthew J. Webber, ${ }^{\dagger}$, \\ $\dagger$ - Department of Chemical \& Biomolecular Engineering, University of Notre Dame \\ *- Address Correspondences to: 205 McCourtney Hall, Notre Dame, IN 46556 USA; \\ mwebber@nd.edu
}

\section{Contents:}

Figure S1- Sequence screening for release at $\mathrm{pH} 5$ and $\mathrm{pH} 7$

Figure S2- FTIR spectroscopy for samples from $\mathrm{pH} 5$ to $\mathrm{pH} 8$

Figure S3- Rheology data for $\mathrm{C}_{10}-\mathrm{V}_{2} \mathrm{~A}_{2} \mathrm{E}_{2}$ at $\mathrm{pH} 5$

Figure S4- Overview of rheology for all samples in $\mathrm{pH}$ and glucose studies

Figure S5- Hydrogel properties assessed in the presence of physiological $\mathrm{Ca}^{2+}$ and $\mathrm{Mg}^{2+}$

Figure S6- Scanning electron microscopy to assess hydrogel porosity

Figure S7- Dasiglucagon release and gel stability with and without GOx

Figure S8- Initial bulk pH drop from incubation of PA hydrogels in glucose buffers

Figure S9- GOx activity via repeated recharging of fresh glucose and $\mathrm{pH}$ monitoring

Figure S10- Circular dichroism spectroscopy of dasiglucagon over time at pH 5

Figure S11- Release studies performed with full buffer exchange

Figure S12- Individual blood glucose traces for each mouse in the hypoglycemic region

Figure S13- Preliminary blood glucose control experiment for gels with and without GOx

Figure S14- ESI-MS of $\mathrm{C}_{10}-\mathrm{V}_{2} \mathrm{~A}_{2} \mathrm{E}_{2}$

Figure S15- Analytical HPLC of $\mathrm{C}_{10}-\mathrm{V}_{2} \mathrm{~A}_{2} \mathrm{E}_{2}$

Figure S16- ESI-MS of dasiglucagon

Figure S17- Analytical HPLC of dasiglucagon

Figure S18- ESI-MS of MCA-dasiglucagon

Figure S19- Analytical HPLC of MCA-dasiglucagon

Figure S20- Circular dichroism spectroscopy of dasiglucagon

Figure S21- Fluorescence spectroscopy and concentration standard curve of MCA-dasiglucagon 

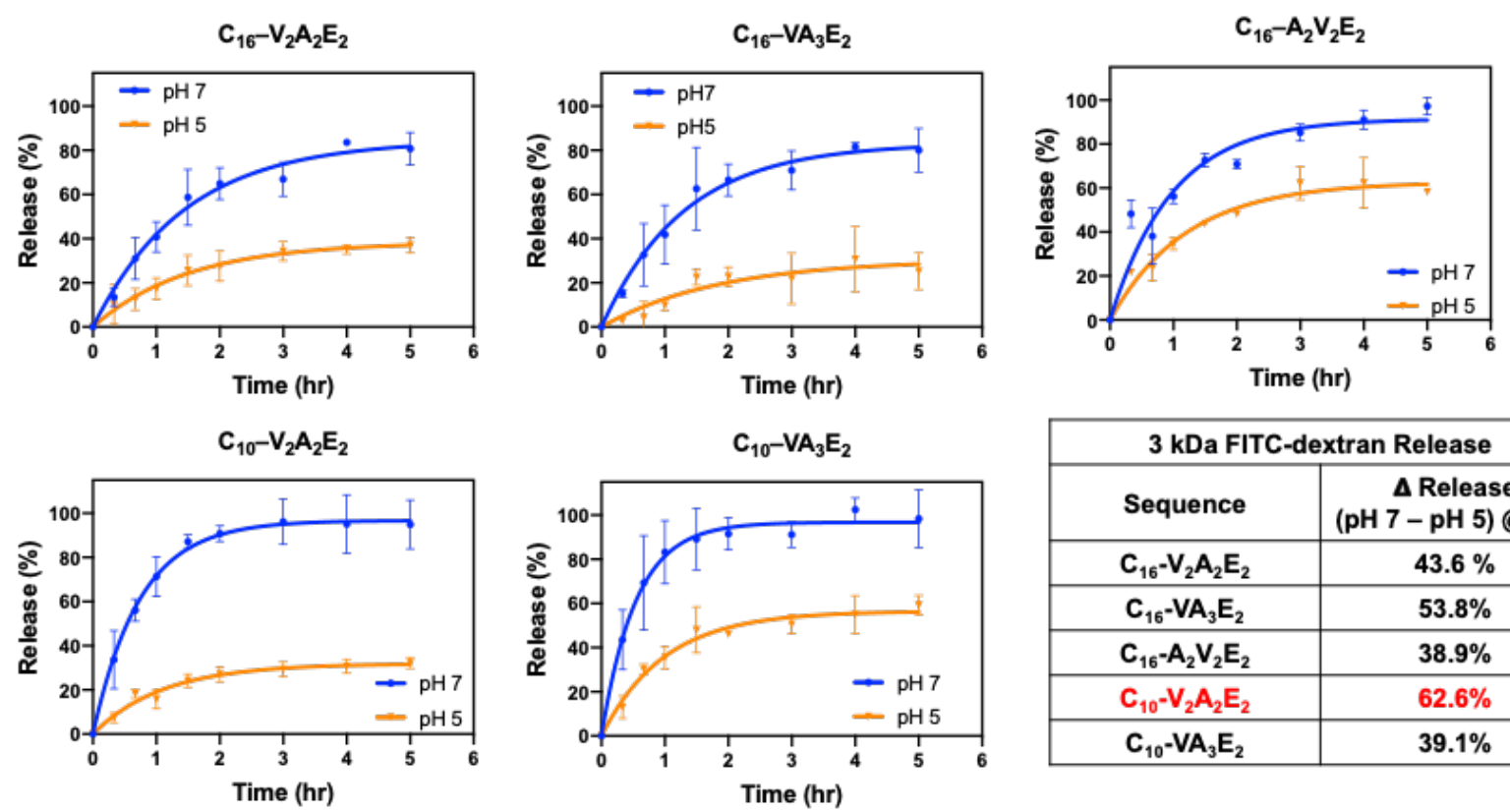

\begin{tabular}{|c|c|}
\hline \multicolumn{2}{|c|}{3 kDa FITC-dextran Release } \\
\hline Sequence & $\begin{array}{c}\Delta \text { Release } \\
(\mathrm{pH} 7-\mathrm{pH} \text { 5) @ 5hr }\end{array}$ \\
\hline $\mathrm{C}_{16}-\mathrm{V}_{2} \mathrm{~A}_{2} \mathrm{E}_{2}$ & $43.6 \%$ \\
\hline $\mathrm{C}_{16}-\mathrm{VA}_{3} \mathrm{E}_{2}$ & $53.8 \%$ \\
\hline $\mathrm{C}_{16}-\mathrm{A}_{2} \mathrm{~V}_{2} \mathrm{E}_{2}$ & $38.9 \%$ \\
\hline $\mathrm{C}_{10}-\mathrm{V}_{2} \mathrm{~A}_{2} \mathrm{E}_{2}$ & $62.6 \%$ \\
\hline $\mathrm{C}_{10}-\mathrm{VA}_{3} \mathrm{E}_{2}$ & $39.1 \%$ \\
\hline
\end{tabular}

Figure S1: pH-dependent release of encapsulated $3 \mathrm{kDa}$ FITC-dextran to screen different PA sequences.
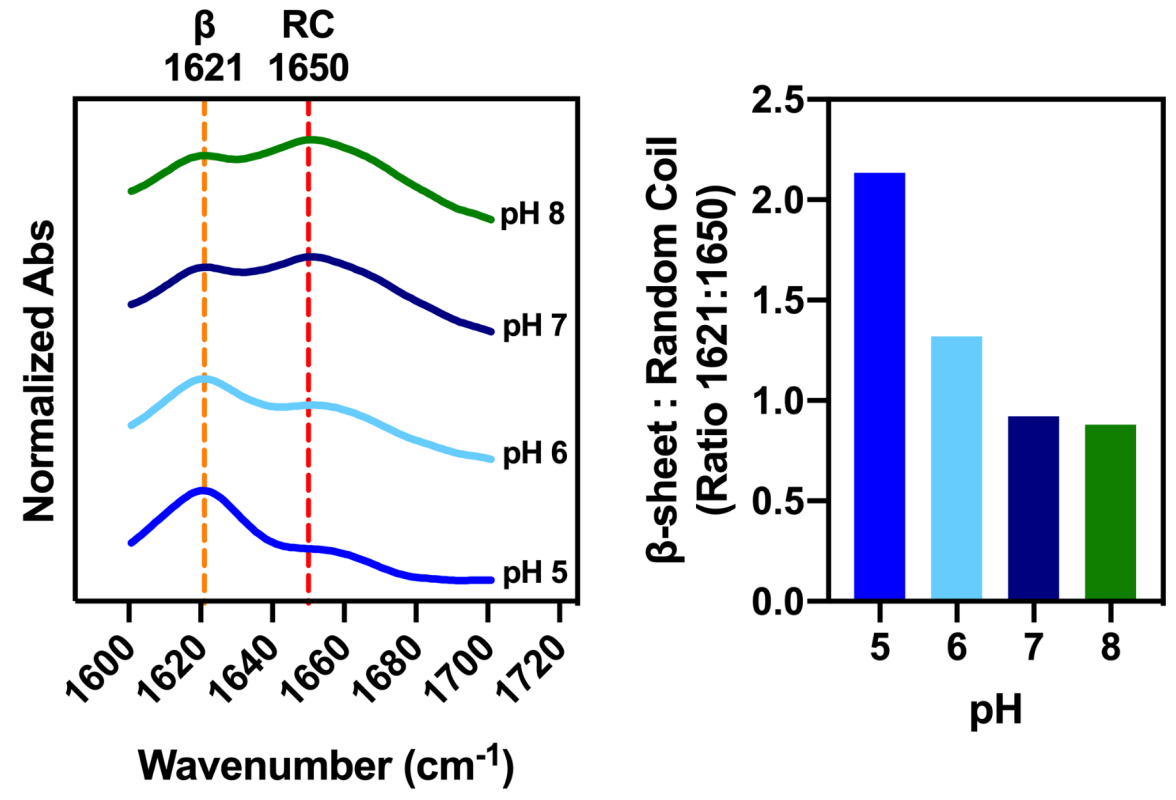

Figure S2: FTIR spectroscopy of samples at various $\mathrm{pH}$ monitoring signal attributed to $\beta$-sheet $\left(\sim 1621 \mathrm{~cm}^{-1}\right)$ and random coil $\left(\sim 1650 \mathrm{~cm}^{-1}\right)$. Normalized spectra are offset on the y-axis to visualize changes with $\mathrm{pH}$. The ratio of these two peaks is then compared at different $\mathrm{pH}$ (right). 

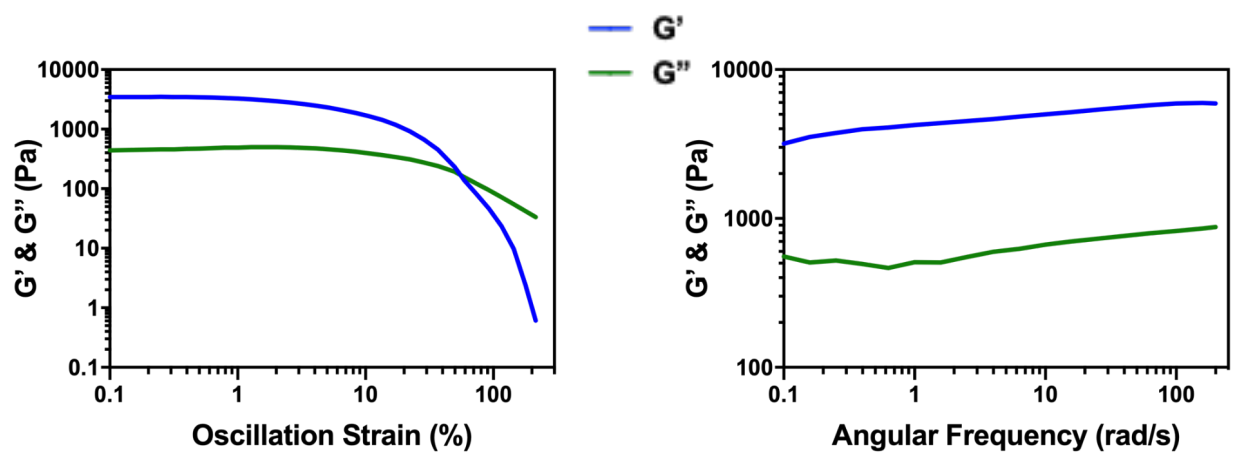

Figure S3: Strain sweep (10 rad/s) and frequency sweep, (1\% strain) for $1 \mathrm{wt} \% \mathrm{C}_{10}-\mathrm{V}_{2} \mathrm{~A}_{2} \mathrm{E}_{2}$ hydrogel in pH 5 buffer.
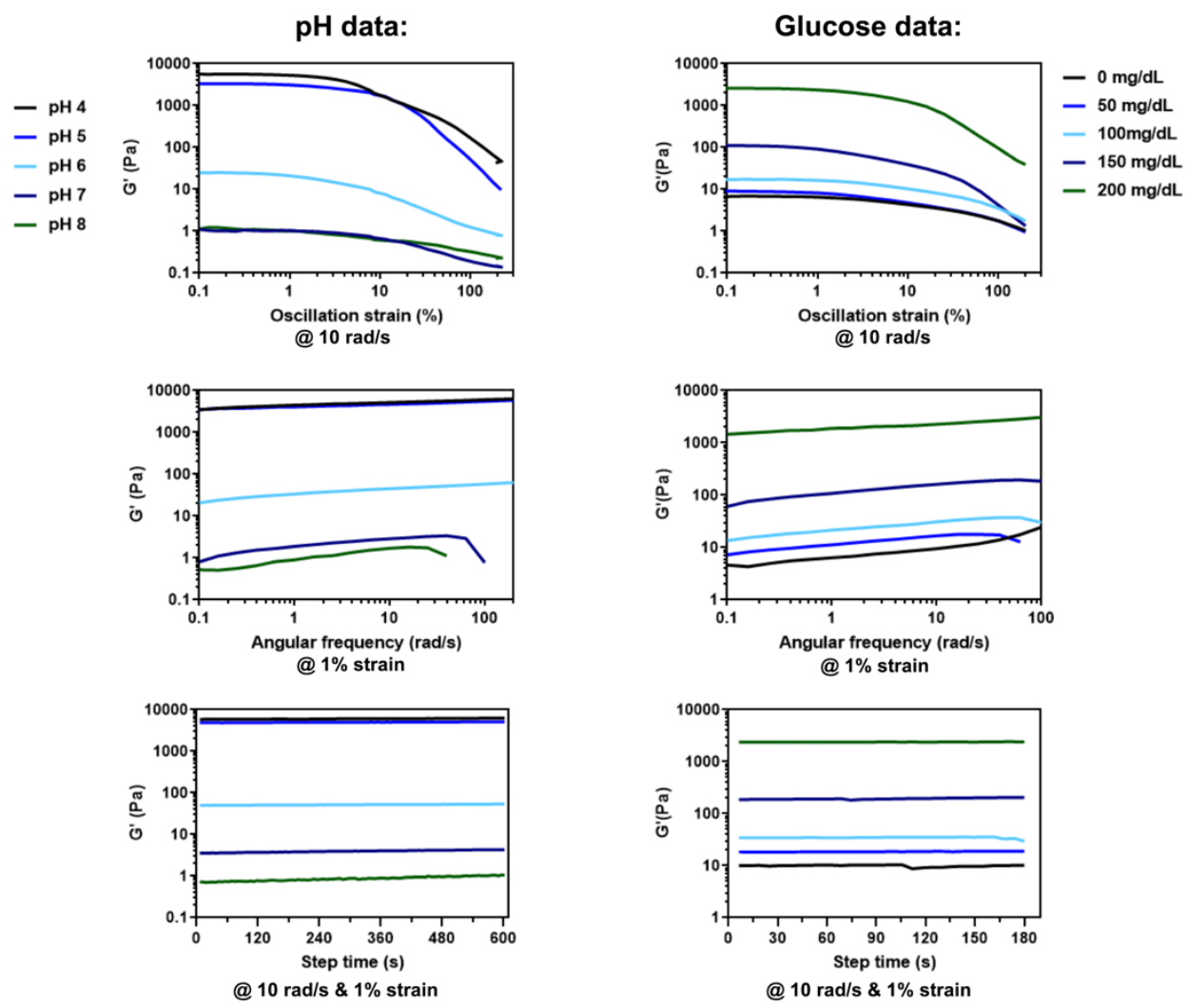

Figure S4: Strain sweep, frequency sweep, and time sweep (1\% strain, $10 \mathrm{rad} / \mathrm{s})$ for $1 \mathrm{wt} \% \mathrm{C}_{10^{-}}$ $\mathrm{V}_{2} \mathrm{~A}_{2} \mathrm{E}_{2}$ hydrogel in all $\mathrm{pH}$ conditions (left) and all glucose conditions (right). Average G' values from the time sweep (bottom) are plotted for the bar graph in the main text. 

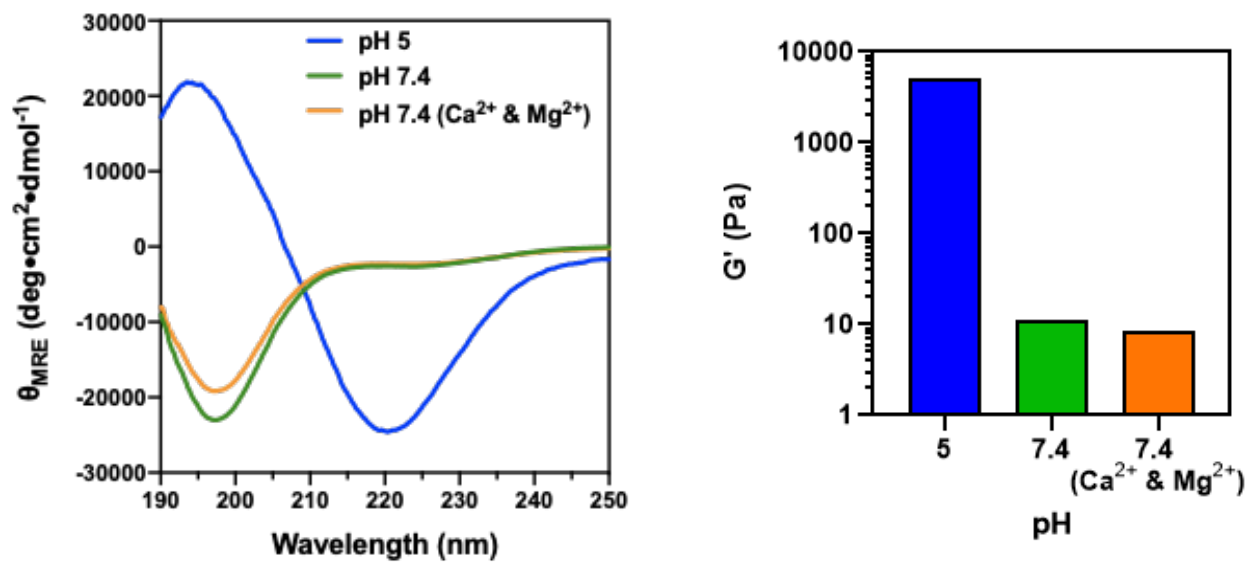

Figure S5: $\mathrm{CD}$ and rheology performed for $\mathrm{pH} 7.4$ buffer the presence of physiological calcium $(0.9 \mathrm{mM})$ and magnesium $(0.5 \mathrm{mM})$ compared to the same samples in a buffer of $\mathrm{pH} 7.4$ and a buffer of $\mathrm{pH} 5$ without addition of the divalent ions.

A

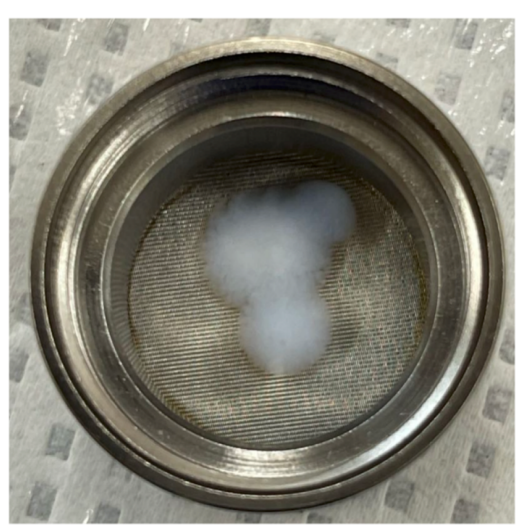

C

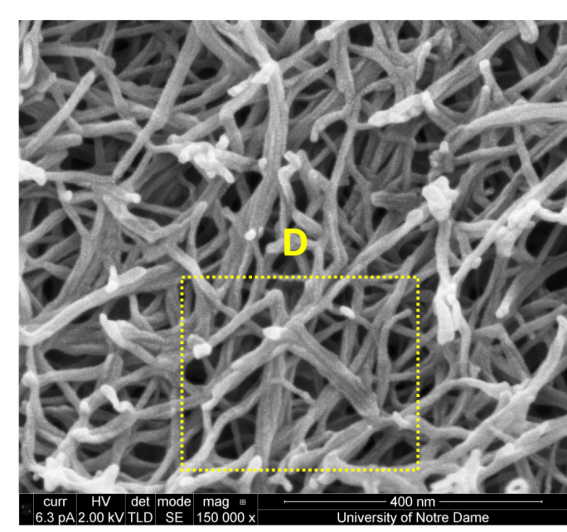

B
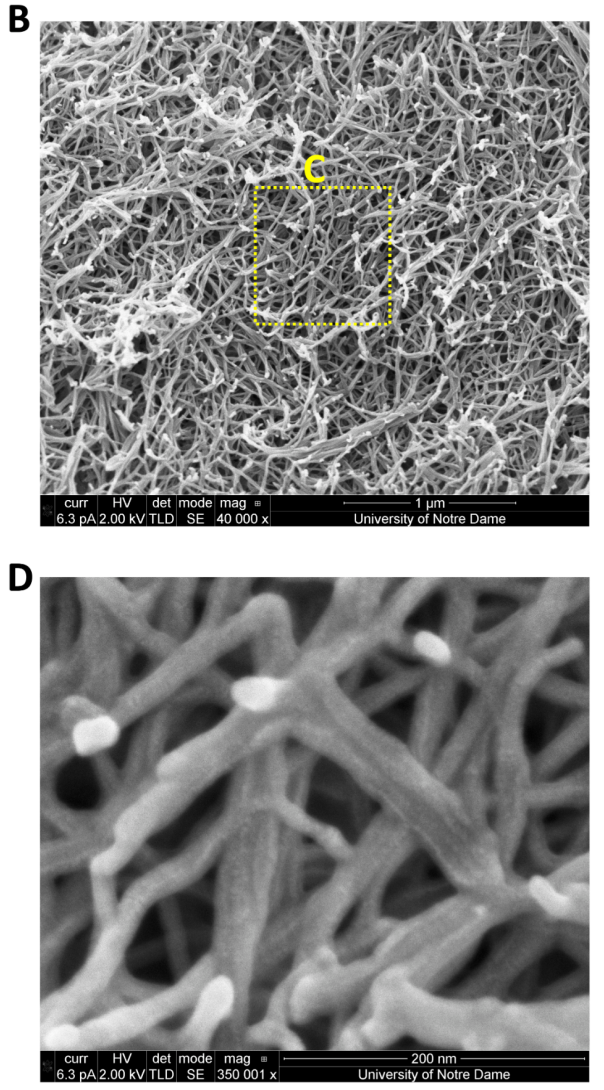

Figure S6: Scanning electron microscopy (SEM) to visualize the highly porous architecture of the nanofibrillar hydrogel networks. Imaging was performed on a sample prepared by ethanol dehydration and critical point drying (A), with increasing magnification of specific regions shown (B-D). 

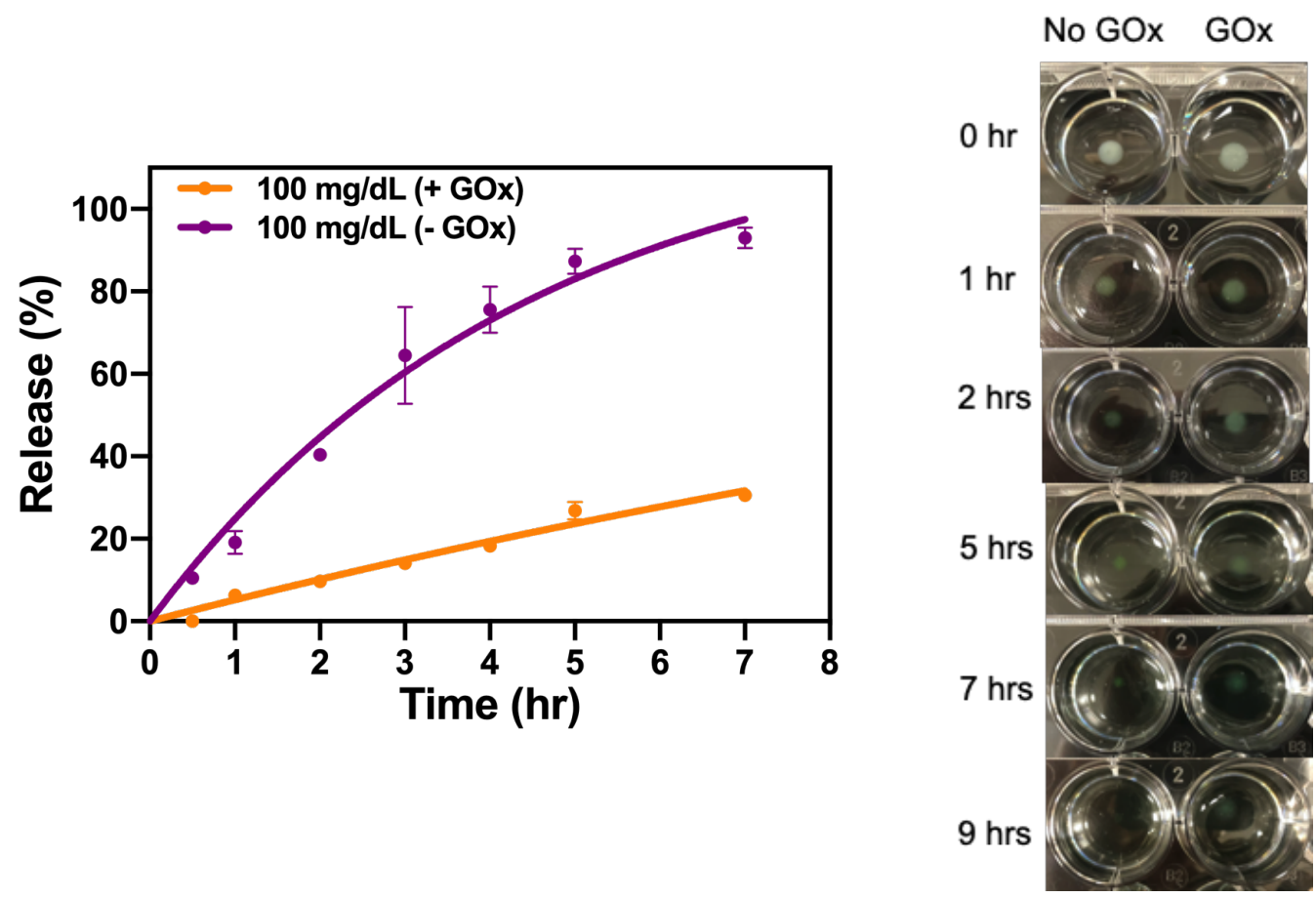

Figure S7: Dasiglucagon release from PA hydrogels prepared with and without GOx and incubated in a bulk buffer containing $100 \mathrm{mg} / \mathrm{dL}$ ( $\mathrm{n}=3 /$ group). (Right) The gels without GOx were completely dissolved by $9 \mathrm{~h}$, whereas the gels with GOx became more transparent but otherwise did not show significant reduction in size.

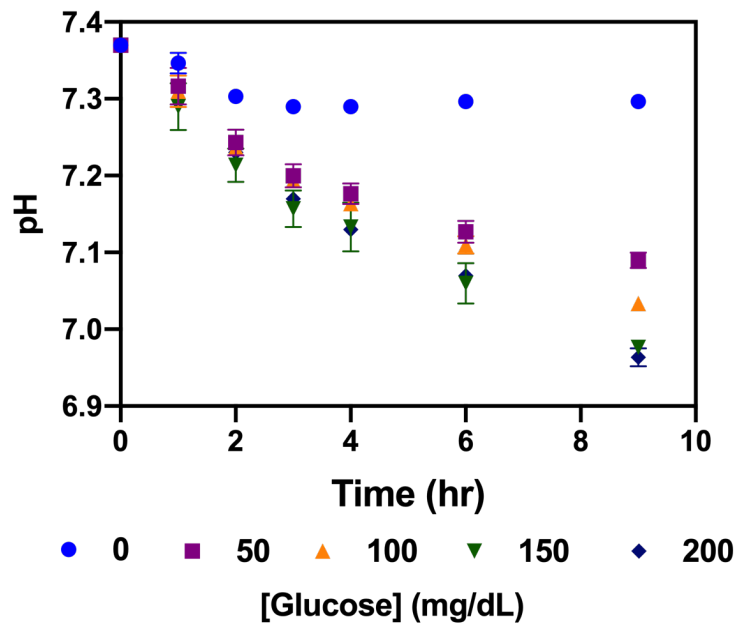

Figure S8: Initial drop in the bulk pH when $100 \mu \mathrm{L}$ PA hydrogels were incubated in $4 \mathrm{~mL}$ of a $\mathrm{pH} 7.4$ buffer containing different amounts of glucose ( $\mathrm{n}=3$ /group). 


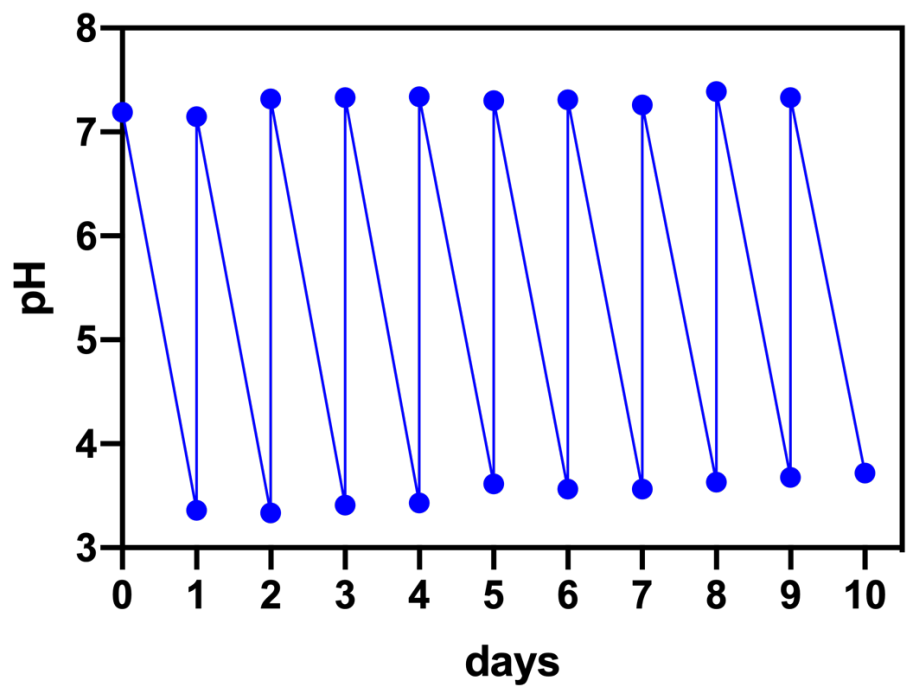

Figure S9: GOx activity assessment via repeated $\mathrm{pH}$ change when $100 \mu \mathrm{L}$ PA hydrogels were incubated in $4 \mathrm{~mL}$ of a $\mathrm{pH} 7.4$ salt solution recharged daily with a fresh bulk phase containing 200 $\mathrm{mg} / \mathrm{dL}$ glucose. $\mathrm{pH}$ was sampled immediately before and after bulk solution exchange. GOx in the hydrogel reduces $\mathrm{pH}$ repeatedly for at least 10 days.

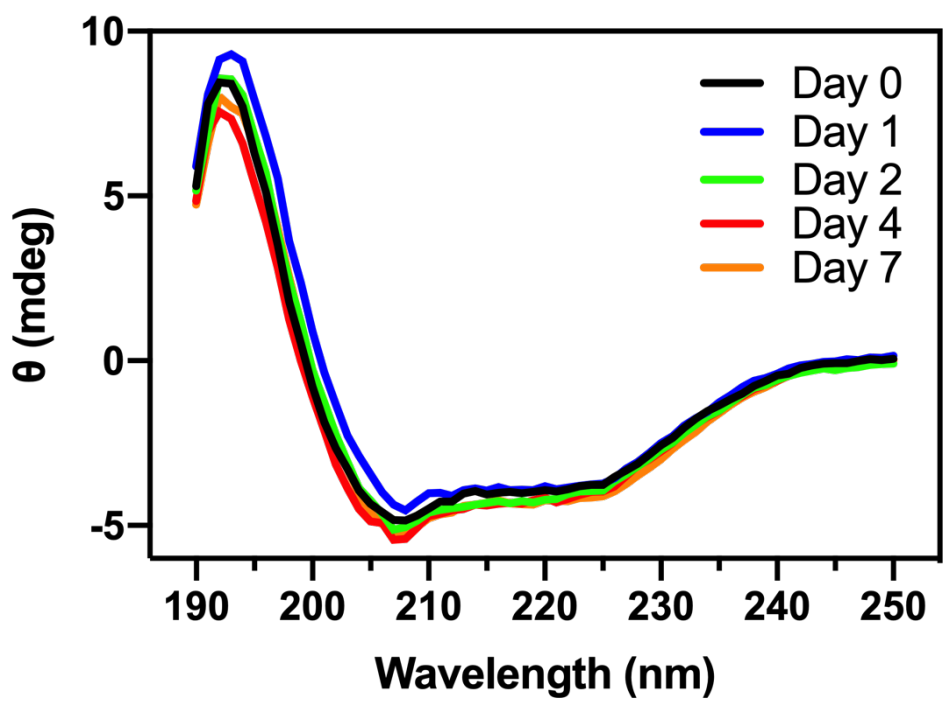

Figure S10: Circular dichroism spectroscopy on dasiglucagon incubated for multiple days in $\mathrm{pH}$ 5 buffer and monitored for preservation of active structure, confirming no formation of degradation or amyloid products for at least 1 week under these conditions. 


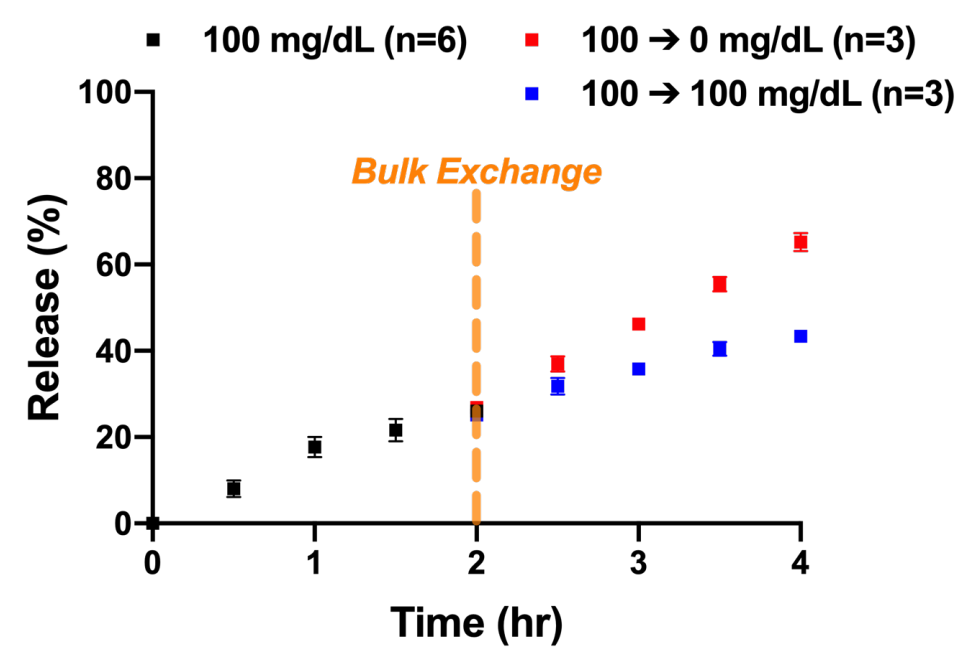

Figure S11: Release studies with full buffer exchange. All samples were incubated at $100 \mathrm{mg} / \mathrm{dL}$ for $2 \mathrm{~h}$, at which time half had buffer fully exchanged for another $100 \mathrm{mg} / \mathrm{dL}$ while half had buffer exchanged for $0 \mathrm{mg} / \mathrm{dL}$.
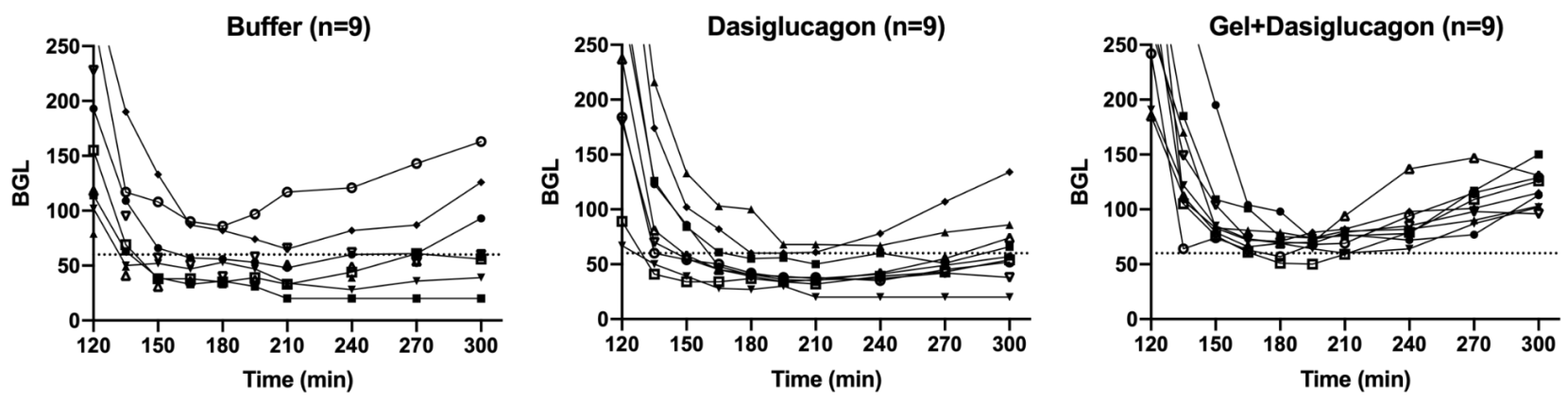

Figure S12: Plotted results of the hypoglycemic region for each individual mouse in the study (n=9/group). 

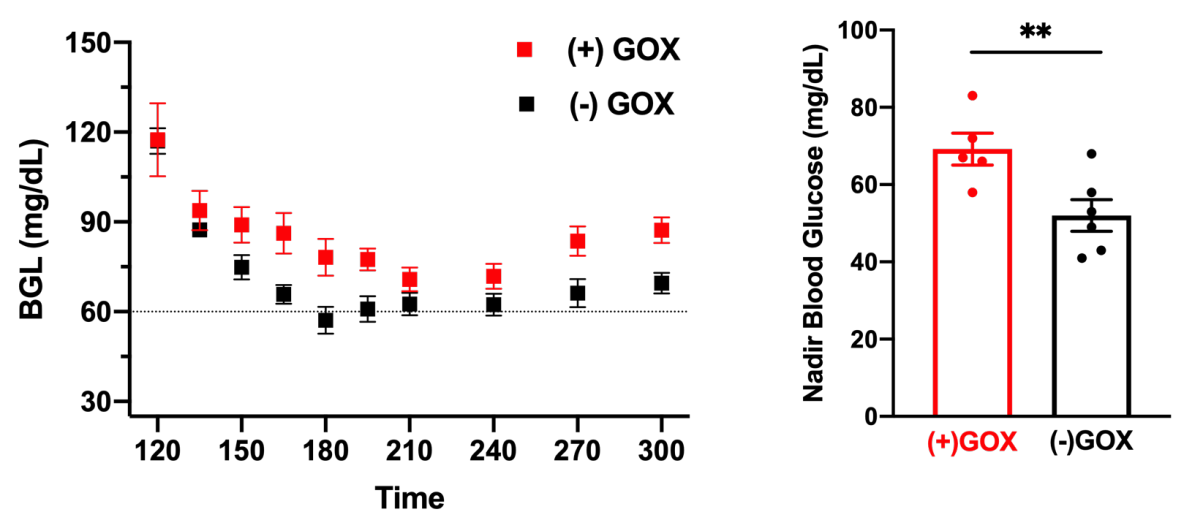

Figure S13: Preliminary experiment assessing the role of GOx actuation in function of the hydrogel system reported here, with glucagon delivered in a PA gel prepared at $\mathrm{pH} 5$ with $(\mathrm{n}=5)$ and without $(n=6)$ GOx. These preliminary studies had been conducted with a modification to the typical control strategy used for other studies herein. Initial glucose control was achieved in this study with $0.75 \mathrm{IU} / \mathrm{kg}$ insulin detemir, and two hours following gel administration insulin (2 IU/kg) was administered to induce hypoglycemia. The extent of hypoglycemia (nadir) was compared between the two groups. ( $* * \mathrm{P}<0.01$ by t-test).

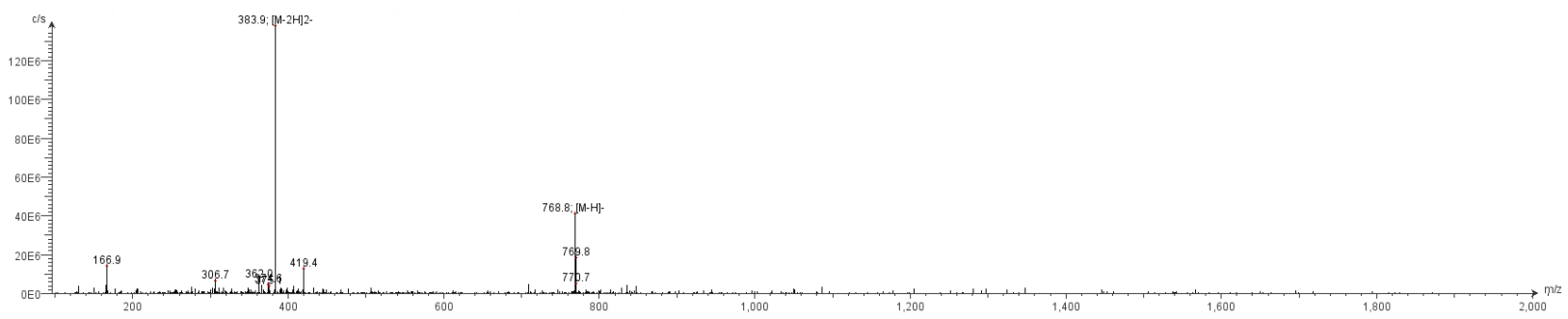

Figure S14: ESI-MS (negative mode) of $\mathrm{C}_{10}-\mathrm{V}_{2} \mathrm{~A}_{2} \mathrm{E}_{2}$. Calculated 769.9 [M], observed 768.8 [M$\mathrm{H}]^{-1}, 383.9[\mathrm{M}-2 \mathrm{H}]^{-2}$. 


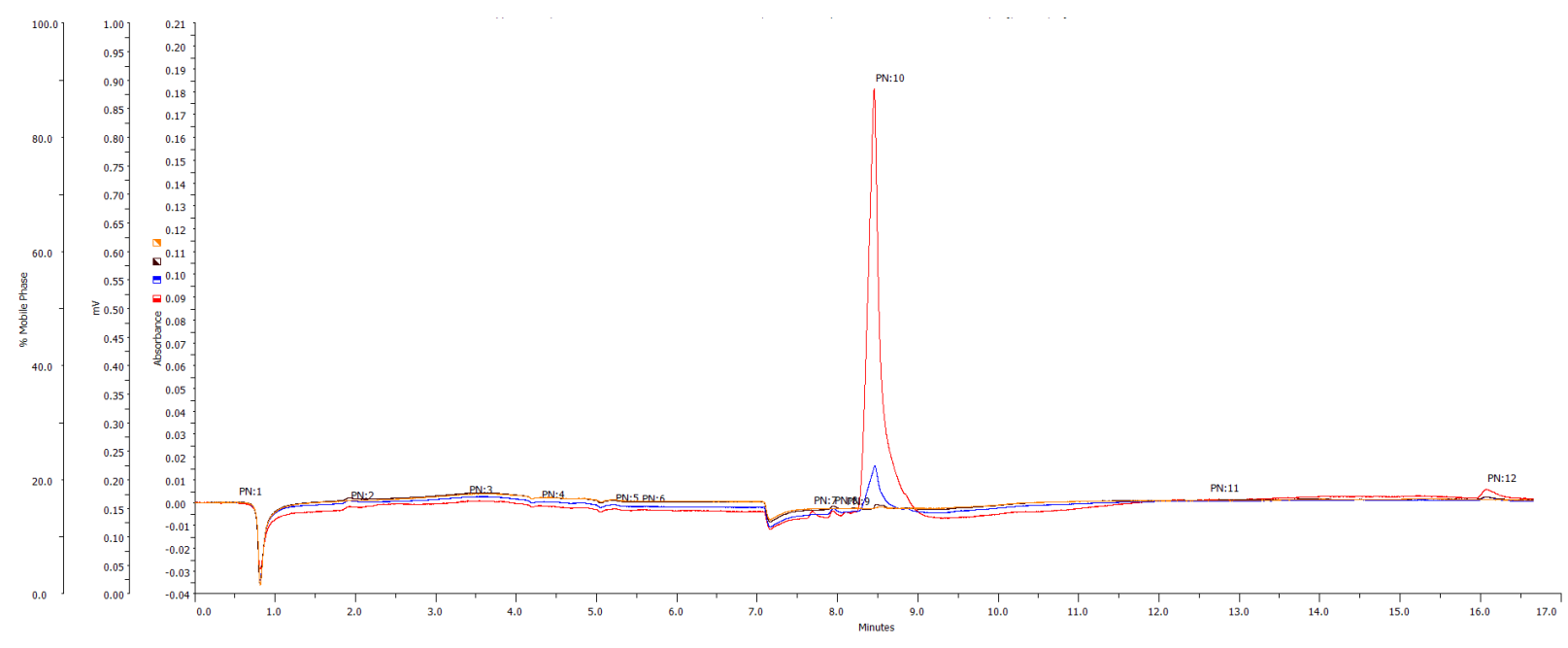

Figure S15: Analytical HPLC of $\mathrm{C}_{10}-\mathrm{V}_{2} \mathrm{~A}_{2} \mathrm{E}_{2}$ with UV absorbance monitored at 220, 260, 280, and $350 \mathrm{~nm}$.

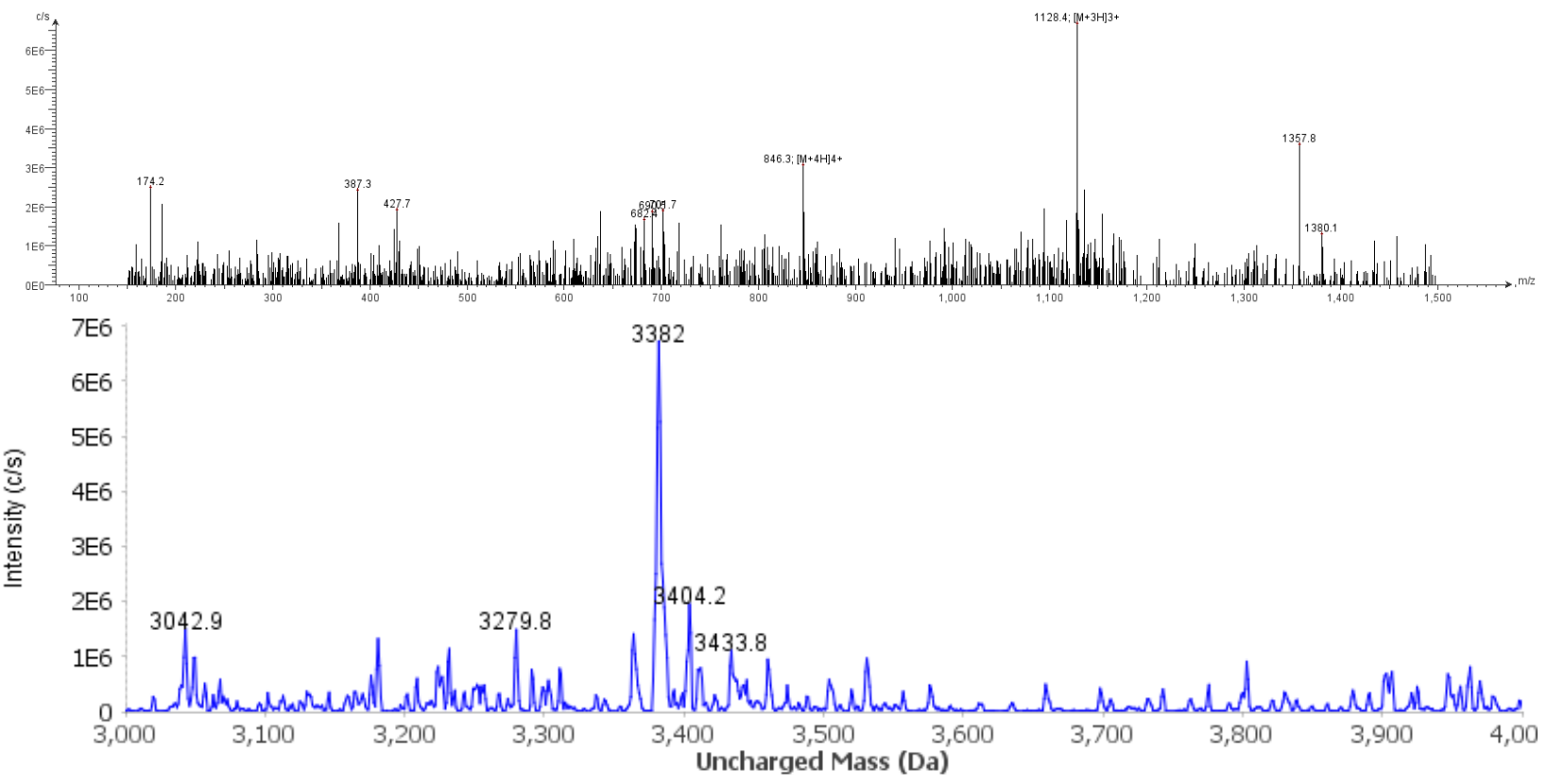

Figure S16: (top) ESI-MS of dasiglucagon (positive mode). Calculated 3381.6 [M], observed $1128.4[\mathrm{M}+3 \mathrm{H}]^{+3}, 846.3[\mathrm{M}+4 \mathrm{H}]^{+4}$; (b) Deconvoluted ESI-MS spectra (uncharged). 


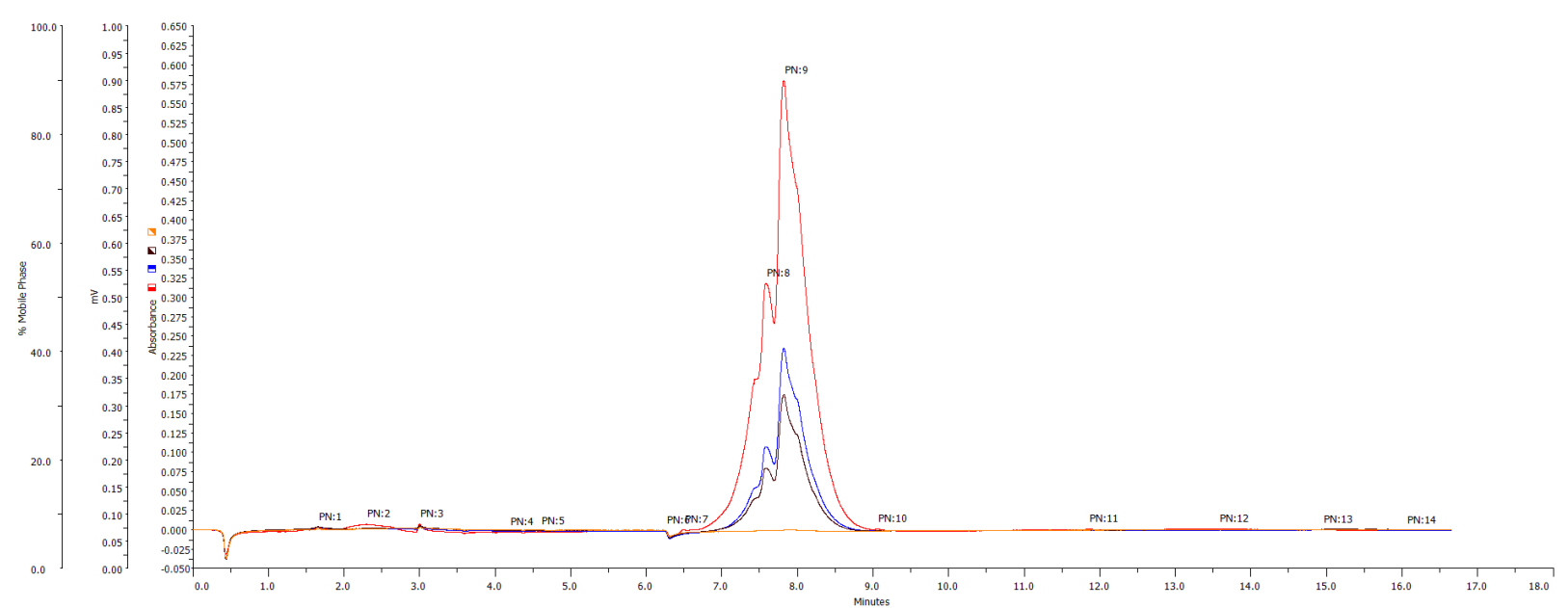

Figure S17: Analytical HPLC of dasiglucagon with UV absorbance monitored at 220, 260, 280, and $350 \mathrm{~nm}$.

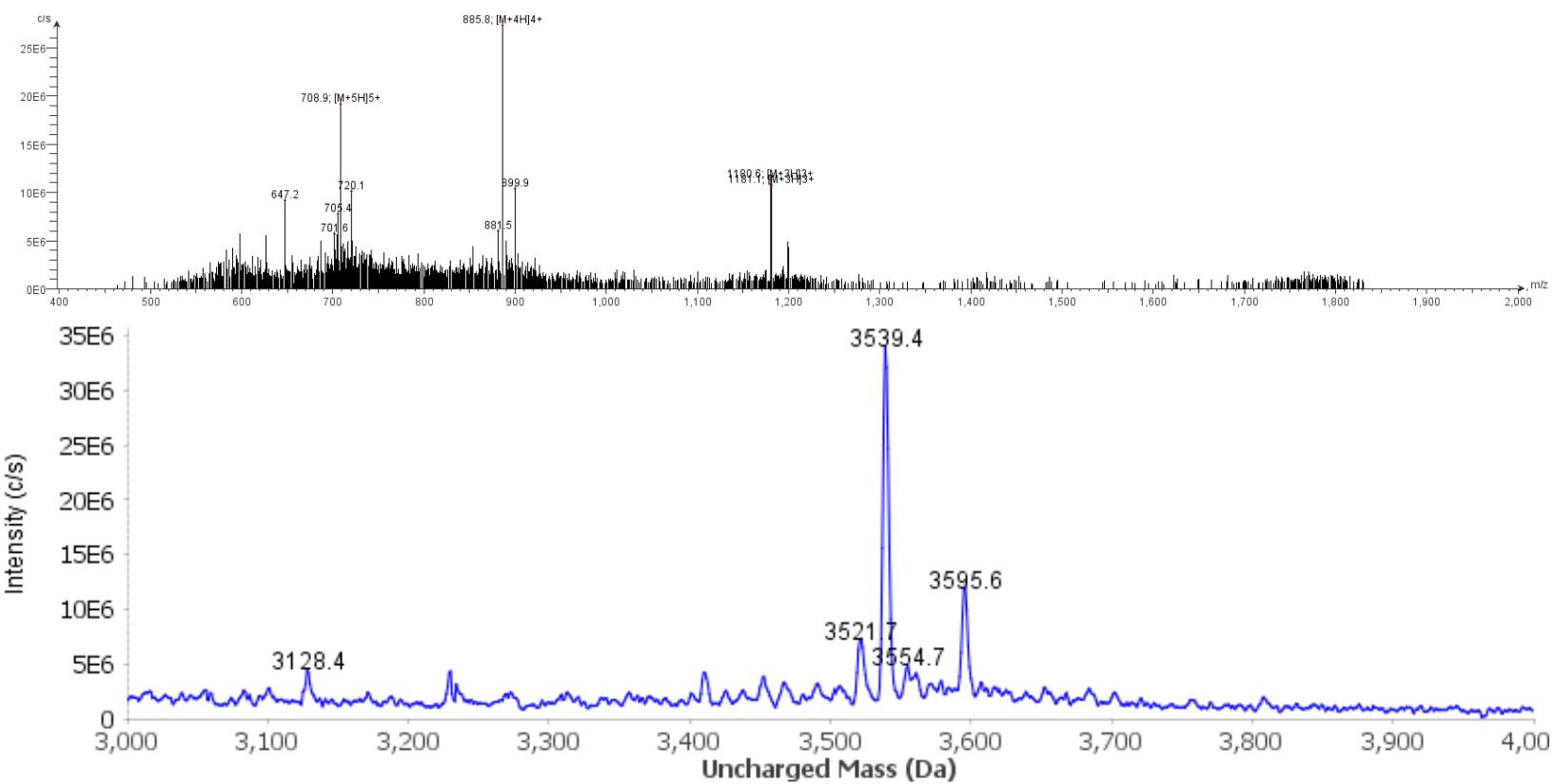

Figure S18: (top)ESI-MS of MCA-dasiglucagon (positive mode). Calculated 3538.8 [M], observed 1180.6 [M+3H $]^{+3}, 885.8[\mathrm{M}+4 \mathrm{H}]^{+4}$; (b) Deconvoluted ESI-MS spectra (uncharged). 


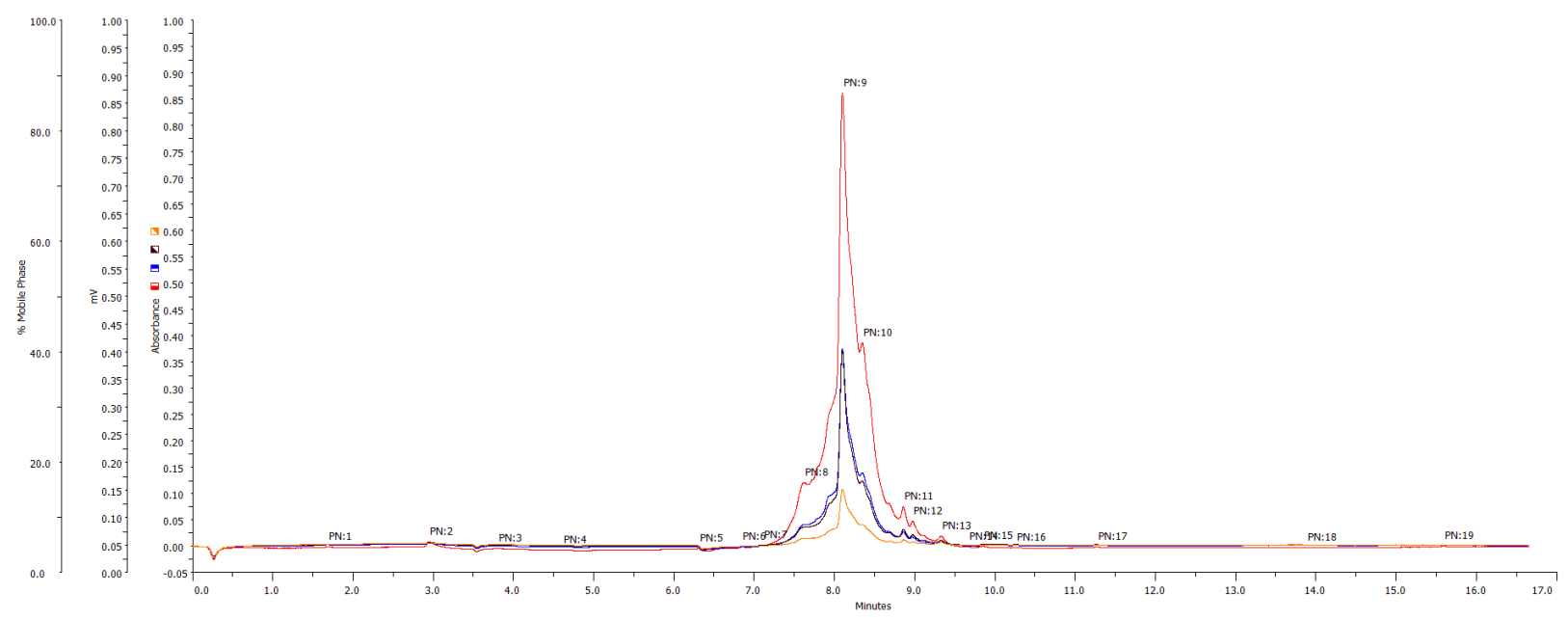

Figure S19: Analytical HPLC of MCA-dasiglucagon with UV absorbance monitored at 220, 260, 280,350nm.

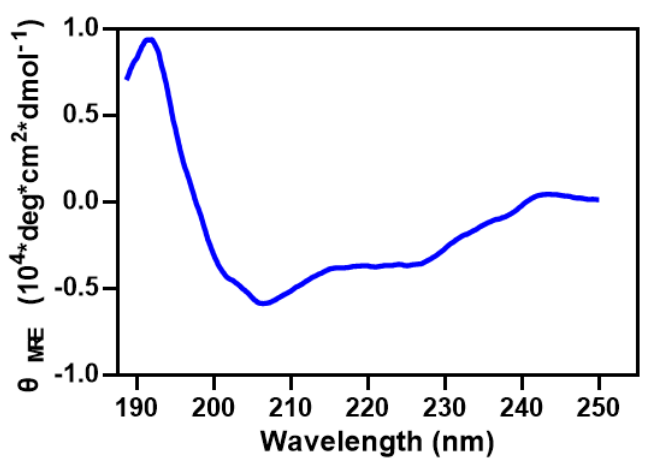

Figure S20: Circular dichroism spectroscopy of dasiglucagon at $0.05 \mathrm{mg} / \mathrm{mL}$ in $50 \mathrm{mM}$ phosphate buffer ( $\mathrm{pH} 7)$. 


\section{Online Supporting Information}
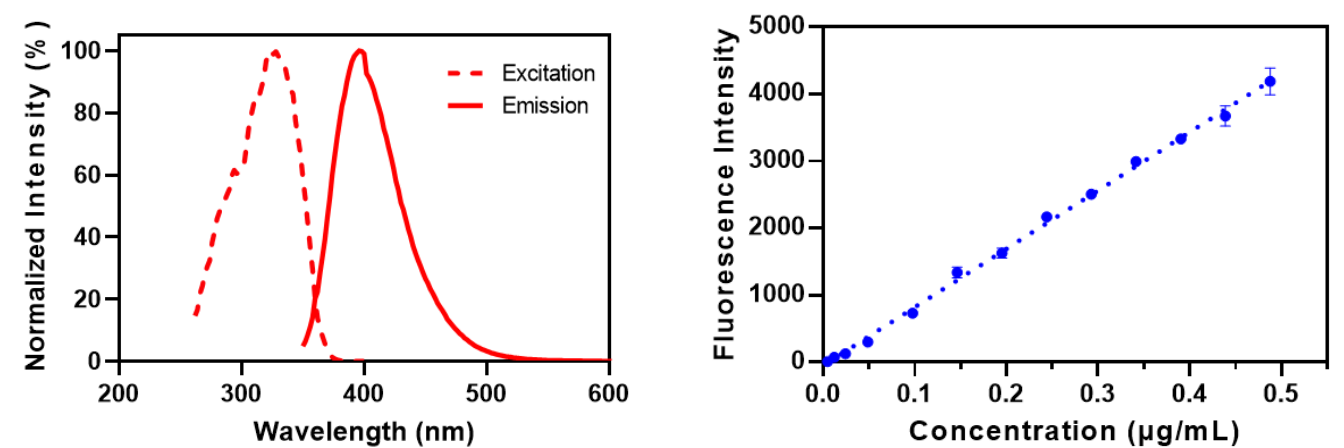

Figure S21: Fluorescent properties of MCA-dasiglucagon: (left) normalized spectra of absorbance (excitation) and fluorescence (emission); (right) standard curve used for concentration determination. 